\title{
PERFIL SOCIODEMOGRÁFICO DE MULHERES EM SITUAÇÃO DE VIOLÊNCIA ASSISTIDAS NAS DELEGACIAS ESPECIALIZADAS
}

Socio-demographic profile for women who faces the violence and get the support at specialized police stations.

Perfil socio-demográfico de mujeres en situación de violencia asistidas en comisarías especializadas

Maria Aparecida Vasconcelos Moura ${ }^{1}$

Leônidas de Albuquerque Netto²

Maria Helena Nascimento Souza ${ }^{3}$

\section{RESUMO}

Pesquisa quantitativa, descritiva, do tipo série histórica, que teve como objetivos: caracterizar a demanda assistida nas Delegacias Especializadas de Atendimento à Mulher (DEAMs) na região metropolitana do Rio de Janeiro quanto ao perfil sociodemográfico, tipo de violência e relação da mulher com o acusado da agressão; e analisar estes dados diante da situação da violência de gênero à luz da discussão temática. Os dados foram coletados a partir de 38.009 registros de ocorrência de violência à mulher no período de 2003 a 2008, cedidos pelo Instituto de Segurança Pública após aprovação pelo Comitê de Ética. As mulheres eram jovens, brancas, com ensino fundamental completo, solteiras e com ocupação. A maioria residia na zona norte da cidade. 0 local de ocorrência do delito foi a residência. Predominou a agressão psicológica. Os agressores eram membros próximos da família. Violência é uma forma de expressão dessas famílias, sendo necessária mudança de paradigma de civilização.

Palavras-chave: Enfermagem. Saúde da mulher. Violência contra a mulher.

\begin{abstract}
It's a historic, quantitative and descriptive research, whose goals are: characterize the demand assisted at Specialized Police Stations in Assistance to Women (DEAMs) located in the city of Rio de Janeiro according to the socio-demographic profile, type of violence and the relationship between the woman and the accused of the assault, and analyze these data on a situation of violence to get a thematic discussion. Data were collected through 38,009 records of violence reports to women during the period of 2003 to 2008, provided by the Public Safety Institute after the approval from the Ethics Committee. The women were young, white, have completed the elementary school, unmarried and employed. The majority lives in the northern area of the city. The place where the crime occurred was their residence. Psychological aggression was predominant. The aggressors are close family members. Violence is the way these families use to express, which requires a paradigm change on the civilization.
\end{abstract}

Keywords: Nursing. Women's health. Violence against women.
Resumen

Investigación cuantitativa, descriptiva, del tipo serie histórica, que tuvo como objetivos: caracterizar la demanda de asistencia en los Departamentos de Policía Especializada para Atención a la Mujer (DEAM) en la región metropolitana de Rio de Janeiro sobre el perfil socio-demográfico, el tipo de la violencia y la relación de la mujer con los acusados del asalto, y analizar los datos sobre la situación de violencia de género a la luz del tema de discusión. Se recogieron datos de 38.009 registros de ocurrencia de la violencia a las mujeres en el período 2003 a 2008, asignados por la Oficina de Seguridad Pública después de la aprobación por el Comité de Ética. Las mujeres eran jóvenes, blancas, con escuela primaria completa, solteras y con ocupación. La mayoría reside en la región norte de la ciudad. El lugar de la ocurrencia de la infracción fue la propia residencia de ellas. La agresión psicológica fue la más predominante. Los autores son miembros cercanos de la familia. La violencia es una forma de expresión de estas familias, que requiere un cambio de paradigma de la civilización.

Palabras clave: Enfermería. Salud de la mujer. Violencia contra la mujer.

\footnotetext{
${ }^{1}$ Professora Doutora Associada III do Departamento de Enfermagem Materno-Infantil da Escola de Enfermagem Anna Nery da Universidade Federal do Rio de Janeiro. Rio de Janeiro - RJ. Brasil. E-mail: maparecidavas@yahoo.com.br ;²Aluno do $8^{\circ}$ período do curso de Enfermagem e Obstetrícia de Escola de Enfermagem Anna Nery do Departamento de Enfermagem Materno-Infantil da Universidade Federal do Rio de Janeiro (UFRJ). Bolsista PIBIC do Núcleo de Pesquisa em Saúde da Mulher (NUPESM), período 2009.2/2011.1. Rio de Janeiro - RJ. Brasil. E-mail: leonidasalbuquerque@bol.com.br; Professora Doutora Adjunta na área da Saúde Coletiva do Departamento de Enfermagem em Saúde Pública da Escola de Enfermagem Anna Nery da Universidade Federal do Rio de Janeiro. Rio de Janeiro - RJ. Brasil. E-mail: mhnsouza@yahoo.com.br.
} 


\section{INTRODUÇÃO}

0 fenômeno da violência contra a mulher atinge essa população em todas as idades, independente de classe social, cultura, grau de instrução, etnia e grau de desenvolvimento do país ${ }^{1}$. Os altos índices de violência registrados nas Delegacias Especializadas de Atendimento à Mulher (DEAMs) e expostos por estudiosos ${ }^{1,2,3}$ da temática nos levam a crer que o número real de mulheres em situação de violência de gênero deve ser maior do que os apresentados nas pesquisas.

Uma das experiências de práticas de aproximação da polícia com os grupos vulneráveis e com os movimentos sociais, no Brasil, deu-se, explicitamente, com a criação das DEAMs. Com essa ação, resultado da luta do movimento feminista contra a violência de gênero, as delegacias especializadas passaram a ser responsáveis pelo registro e apuração de crimes contra a mulher, pelo seu enfrentamento e prevenção, representando, assim, o início da desnaturalização e do controle dessa ação violenta, que passou, então, a ser considerada um problema de interesse público².

A institucionalização das práticas sociais contra a violência de gênero que resultou na criação das Delegacias da Mulher pode ser entendida como parte do processo de consolidação da democracia em curso no país, no qual as mulheres passaram a ter, em princípio, garantia de direitos sociais, proteção policial e acesso à justiça. Nesse cenário, a violência contra a mulher passou a ser considerado uma questão de direitos humanos ${ }^{2}$.

Um estudo realizado no Brasil em 2001 revela que 2,1 milhões de mulheres já sofreram espancamentos graves e aproximadamente 175 mil mulheres são agredidas por mês ${ }^{3}$. Estes resultados nos alertam para uma cruel realidade em que a violência contra a mulher ocorre em grandes proporções, representando um caráter endêmico.

Apesar da situação frequente, apresentando prevalência mais alta do que muitas patologias, esse tipo de violência sofre uma invisibilidade de origem social. Destacam-se os eventos violentos sofridos pelas próprias mulheres que naturalizam, banalizam e relativizam a violência que sofrem e, o que é pior, não as percebem como tal. Além disso, há a difusão da ideia de que a violência entre um homem e uma mulher é um problema que só pode ser resolvido pelos envolvidos 4 .

Verifica-se que a problemática da violência que atinge grande parte da população feminina é um dos graves problemas de Saúde Pública, presente hoje em nossa sociedade. De uma forma geral, a violência está entre as principais causas de morte da população com maior força de trabalho, ou seja, economicamente ativa, que ocupa uma faixa etária entre 15 e 44 anos, o que corresponde à fase reprodutiva da mulher 5 .
Existe uma ordem social de tradição que consente em um determinado padrão de violência contra as mulheres, sendo que o homem tem uma função ativa na relação social e sexual nos relacionamentos, e a sexualidade feminina está limitada à passividade. Se o homem é o provedor da família, ele tem um domínio econômico, assim a dependência financeira feminina explica a aceitação de seus "deveres conjugais", que incluem o sexo ${ }^{3}$.

A violência praticada contra as mulheres é conhecida como violência de gênero porque relaciona-se à condição de subordinação da mulher na sociedade, incluindose nesse contexto a agressão física, sexual e a psicológica ${ }^{6}$.

A desigualdade de gênero constitui uma das grandes contradições da sociedade que se mantém ao longo da história da civilização e tem colocado as mulheres em um lugar social de subordinação. Essa desigualdade tem como uma de suas extremas formas de manifestação a violência contra as mulheres, que é resultado de uma assimetria de poder traduzido em relações de força e dominação. Desse modo, a violência baseada no gênero tem se constituído em um fenômeno social que influencia sobremaneira o modo de viver, adoecer e morrer das mulheres ${ }^{7}$.

No final da década de 60, a partir de estudos sobre as relações familiares, o papel tradicional da mulher na família e a condição feminina na sociedade, a violência doméstica passou a ter visibilidade como um problema social e de saúde, tornando-se uma categoria política de reivindicação feminista que não respeita fronteira, não só de gênero, como também de idade, classe social, etnia, religião e grau de escolaridade ${ }^{8}$.

0 estudo das características sociodemográficas das mulheres em situação de violência justifica-se pelo aumento da visibilidade sobre a temática, no intuito de conscientizar a sociedade sobre a situação da violência de gênero, subsidiar a formulação de políticas públicas e estimular a notificação dos casos no âmbito individual e institucional. Além disso, a elucidação deste fenômeno é de interesse do Instituto de Segurança Pública (ISP) devido à escassez de estudos correlatos sobre a situação de violência contra a mulher na região metropolitana do Rio de Janeiro.

A relevância está na ampliação dos conhecimentos por parte dos profissionais e estudantes da área de saúde acerca dos problemas que envolvem as mulheres que vivenciam agressões físicas e sexuais, abusos, castigos, punições corporais, desqualificação moral, humilhação e maus tratos de ordem psicológica. De fato, acreditamos que a compreensão dessa realidade seja um dos caminhos para aprimorar a atenção conferida nos serviços a este grupo, a partir do dimensionamento do fenômeno da violência e elucidação da dinâmica dos seus 
determinantes.

Paralelamente, almejamos ampliar a divulgação e orientação das questões abordadas, com o objetivo de conscientizar e mobilizar da sociedade civil, reafirmando o direito à cidadania, mediante o incentivo à denúncia e intolerância aos atos agressivos praticados contra a mulher, de qualquer natureza.

Estima-se que o número de casos não notificados de mulheres em situação de violência praticada por parceiro íntimo seja muito grande. Fatores como medo do agressor e vergonha da sociedade fazem com que estas mulheres não denunciem seus companheiros. Por outro lado, muitas não reconhecem a situação vivida como violência? .

Esta pesquisa teve como objetivos caracterizar a demanda assistida nas Delegacias Especializadas de Atendimento à Mulher (DEAMs) na região metropolitana do Rio de Janeiro quanto ao perfil sociodemográfico, tipo de violência e relação da mulher com o acusado da agressão; e analisar estes dados diante da situação da violência de gênero à luz da discussão temática.

\section{MÉTODOS}

0 desenho de estudo desenvolvido foi quantitativo, transversal, descritivo, do tipo série histórica, a partir dos registros de ocorrência de violência contra mulheres em Delegacias Especializadas de Atendimento à Mulher da região metropolitana do Rio de Janeiro, no período de 2003 a 2008. 0 recorte temporal justifica-se pela existência de dez DEAMs, das quais três estão na cidade do Rio de Janeiro (Centro, Jacarepaguá e Campo Grande). As outras se distribuem entre os municípios de Duque de Caxias, São João de Meriti, Nova Iguaçu, São Gonçalo, Niterói, Volta Redonda e Nova Friburgo ${ }^{10}$, correspondendo à região metropolitana.

A amostra foi composta por 38.009 mulheres que vivenciaram a violência de gênero e realizaram seus registros nas Delegacias Especializadas de Atendimento à Mulher, da região metropolitana do Rio de Janeiro.

A coleta de dados foi realizada mediante os dados secundários, cedidos pelo Instituto de Segurança Pública (ISP) sob o Termo de Responsabilidade $n^{\circ}$ 03/ISP/RJ/ NUPESP/151/2009, contendo as informações sobre os atendimentos das DEAMs. 0 Termo de Confidencialidade garantiu o acesso restrito aos pesquisadores envolvidos com o material de pesquisa. 0 projeto foi aprovado pelo Comitê de Ética em Pesquisa da Escola de Enfermagem Anna Nery - Hospital Escola São Francisco de Assis, sob o protocolo no. 73/2009.
Um instrumento foi elaborado, a fim de organizar as informações contidas na base de dados do ISP, possibilitando a análise anual da ocorrência dos fatos durante o período estudado. As variáveis do estudo foram estabelecidas com base nas informações disponíveis no banco de dados, tais como: idade (menor que 19, 20 a 39, 40 a 59 e 60 anos ou mais), cor (branca, parda, negra, ignorada), escolaridade (nenhuma, ensino fundamental, ensino médio, ensino superior), situação conjugal (casada, solteira, outra), ocupação (sim ou não), local de residência da vítima (zona do município, fora do município, ignorado), local de ocorrência da violência (estabelecimento público, residência, via pública, outro), tipo de delito/violência (física, psicológica, sexual, outro) e relação entre o acusado e a vítima (pessoa conhecida, desconhecida, ignorada).

Em decorrência do quantitativo de informações referentes a cada uma das variáveis, houve a necessidade de processar os dados através do Programa Epi-Info 2000 versão 3.5.1 e apresentá-las na forma de tabelas. Na análise descritiva foram calculadas as frequências absolutas e relativas, sendo que, para as variáveis sociodemográficas, foram calculados os respectivos intervalos de $95 \%$ de confiança (Tabela 1).

Para técnica de obtenção dos dados foi fornecido aos pesquisadores um CD contendo as informações sobre os atendimentos das mulheres nas DEAMs da região metropolitana do Rio de Janeiro. Esta fonte de dados foi fornecida pelo Núcleo de Pesquisa em Justiça Criminal e Segurança Pública do Estado do Rio de Janeiro através de um termo de responsabilidade assinado e entregue pessoalmente pela assessora chefe da mesma instituição. 0 documento foi preenchido e assinado, na mesma data, pela pesquisadora principal responsável pelo projeto de pesquisa. $A$ organização das informações e suas variáveis possibilitou a análise anual da ocorrência dos fatos a respeito de mulheres que passaram por situações de violência, e a busca dos objetivos propostos.

\section{RESULTADOS E DISCUSSÃO}

Com o propósito de desenvolver uma análise das principais características da demanda assistida e o perfil sociodemográfico das mulheres que registraram nas DEAMs, pelo menos uma vez, em boletim de ocorrência a agressão sofrida por pessoa conhecida ou desconhecida, ou, em muitos casos, por parceiro íntimo, foi possível o aprofundamento da discussão desses resultados. 


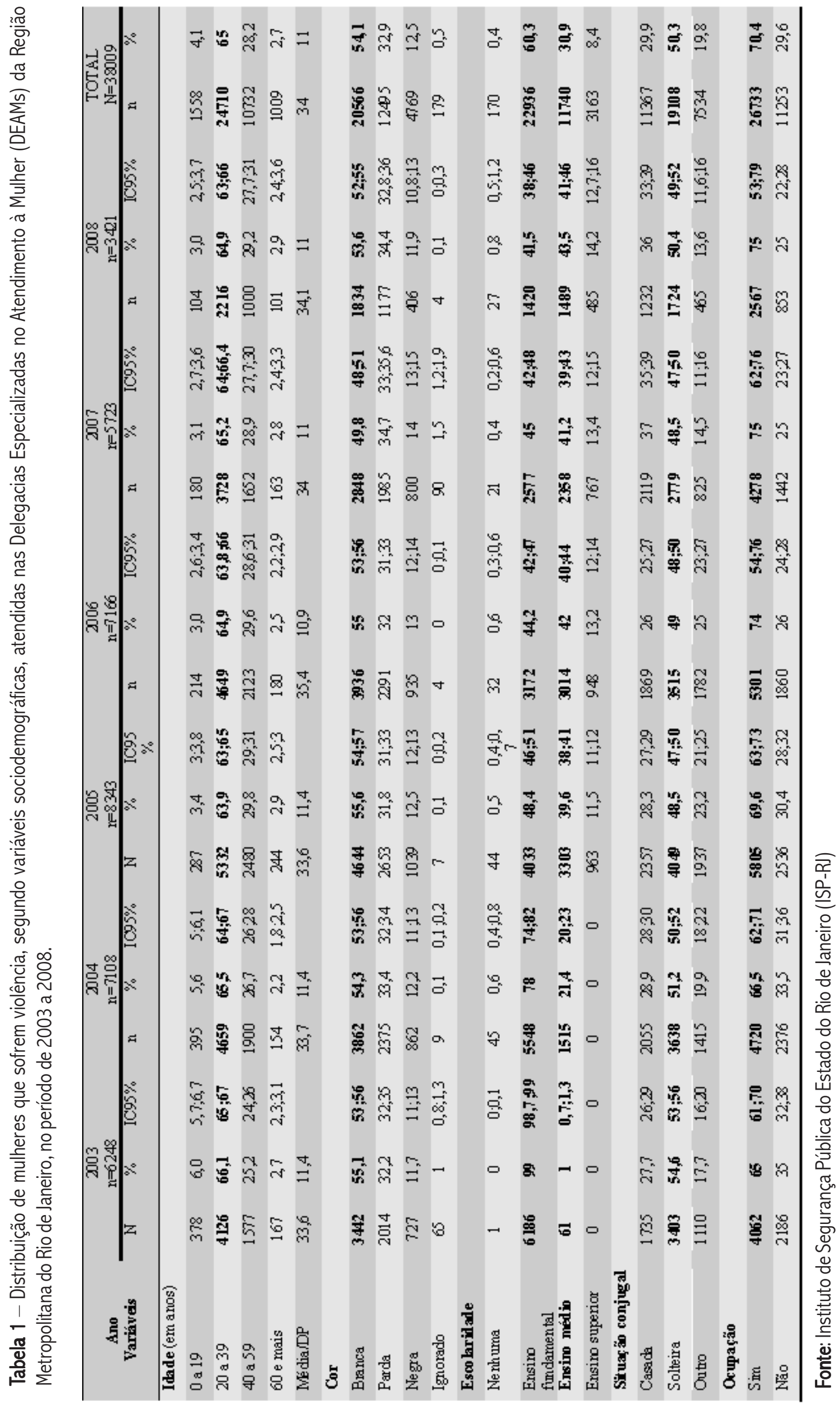


Em relação à idade dessas mulheres, evidenciou-se uma predominância de aproximadamente 24.710 , cerca de $65 \%$, na faixa etária entre 20 e 39 anos, ressaltando a preocupação dos autores por ser a idade reprodutiva e economicamente ativa das mulheres. Os dados mostraram também uma representação de 2,7\% de violência de gênero em mulheres idosas.

No que se refere à cor das mulheres estudadas em situação de violência, verificou-se nos registros que há uma predominância de 20.566 (54,1\%) de mulheres de etnia branca, as quais são reconhecidas por denunciarem mais a agressão, o que não implica necessariamente que estas sejam as mais vitimadas, considerando a subnotificação de outros grupos étnicos.

Em relação à escolaridade, foi constatada que há uma diferença significativa entre aquelas que têm o ensino fundamental completo, com 22.936 mulheres, correspondendo a $60,3 \%$, o que representa quase o dobro comparado àquelas com o ensino médio completo, representando $11.740(30,9 \%)$.

De todas as 38.009 mulheres em situação de violência, no que concerne à situação conjugal, cerca da metade, 19.108 (50,3\%), era solteira. É difícil afirmar que este grupo realmente é o mais afetado pela violência, considerando também que as mulheres casadas se submetem à violência sem registrá-la, por não visualizarem o problema como uma violação de seus direitos e dependência a que são submetidas.

Outro elemento neste núcleo temático é a questão de as mulheres que sofrem com a violência de gênero terem ou não alguma ocupação. Considerando a diversidade das atividades laborais nos resultados da pesquisa e no intuito de facilitar a análise, determinamos a ocupação àquelas mulheres que indicavam um trabalho remunerado. Nesse sentido, a maioria das mulheres, 26.733, tem alguma ocupação, representando $70,4 \%$ da totalidade nesse estudo.

As informações contidas na Tabela 2 esclarecem a respeito do local de residência destas mulheres. Por haver uma grande diversificação de bairros na região metropolitana do Rio de Janeiro, foi preciso agrupá-los por zonas, denominando-as Zona Norte, Zona Sul, Zona Oeste, Centro e Outros Municípios da Região Metropolitana do Estado do Rio de Janeiro, facilitando a compreensão da análise. No conjunto nomeado como Outros Municípios, os que têm maiores índices de violência são: Belford Roxo, Duque de Caxias, Niterói, Nova Iguaçu, São Gonçalo e São João de Meriti.

Tabela 2 - Distribuição de mulheres que sofrem violência e são atendidas nas Delegacias Especializadas no Atendimento à Mulher (DEAMs) da Região Metropolitana do Rio de Janeiro, segundo variáveis relacionadas ao delito, no período de 2003 a 2008.

\begin{tabular}{|c|c|c|c|c|c|c|c|c|c|c|c|c|c|c|}
\hline \multirow{2}{*}{$\begin{array}{c}\text { Ano } \\
\text { Variáve's }\end{array}$} & \multicolumn{2}{|c|}{$\begin{array}{c}2003 \\
n=6248\end{array}$} & \multicolumn{2}{|c|}{$\begin{array}{r}2004 \\
\mathrm{Y}=7108\end{array}$} & \multicolumn{2}{|c|}{$\begin{array}{c}2005 \\
\mathrm{Y}=8343\end{array}$} & \multicolumn{2}{|c|}{$\begin{array}{c}2006 \\
n=7166\end{array}$} & \multicolumn{2}{|c|}{$\begin{array}{c}2007 \\
n=5723\end{array}$} & \multicolumn{2}{|c|}{$\begin{array}{c}2008 \\
\mathrm{TF}=3421\end{array}$} & \multicolumn{2}{|c|}{$\begin{array}{l}\text { TOTAL } \\
\text { YF } 38000\end{array}$} \\
\hline & $n$ & $\%$ & $n$ & $\%$ & $\mathrm{H}$ & $\%$ & $\mathrm{n}$ & $\%$ & $n$ & $\%$ & $n$ & $\%$ & $\mathrm{H}$ & $\%$ \\
\hline \multicolumn{15}{|l|}{$\begin{array}{l}\text { Localde } \\
\text { residêcia da } \\
\text { víima }\end{array}$} \\
\hline Zona Sul & 678 & 109 & 730 & 10,3 & 806 & 9,7 & 780 & 10,9 & 578 & 10 & 305 & 8,9 & 3878 & 102 \\
\hline Zoma Oeste & 510 & 8,3 & 587 & 8,3 & 755 & 9,1 & 579 & 8 & 453 & 7,8 & 278 & 8,1 & 3162 & 8,3 \\
\hline Centro & 1260 & 20,1 & 1454 & 20,5 & 1469 & 17,6 & 1361 & 19 & 1160 & 202 & 729 & 21,2 & 7433 & 19,5 \\
\hline Outro municipio & 191 & 3,0 & 231 & 32 & 317 & 3,8 & 208 & 2,9 & 151 & 2,6 & 114 & 3,3 & 1212 & 3,2 \\
\hline Ignorado & 8 & 0,1 & 6 & 0 & 12 & 0,1 & 38 & 0,6 & 151 & 2,6 & 43 & 1,3 & 258 & 0,7 \\
\hline \multicolumn{15}{|l|}{$\begin{array}{l}\text { Localde } \\
\text { ocorrência da } \\
\text { violência }\end{array}$} \\
\hline $\begin{array}{l}\text { Estabelecimerto } \\
\text { público }\end{array}$ & 79 & 1,3 & 168 & 2,4 & 766 & 9,1 & 648 & 8,9 & 615 & 10,7 & 362 & 10,6 & 2638 & 6,9 \\
\hline Resid êcia & 4282 & 685 & 5123 & 72 & 6085 & 73 & 5206 & 72,7 & 3986 & 69,6 & 2430 & 71 & 27112 & 71,4 \\
\hline Via Pública & 1572 & 25,1 & 1389 & 19,5 & 1345 & 16,1 & 1187 & 16,6 & 1038 & 182 & 552 & 16,1 & 7063 & 18,6 \\
\hline Outro & 315 & 5,1 & 428 & 6,1 & 147 & 1,8 & 125 & 1,8 & 84 & 1,5 & $n$ & 2,3 & 1176 & 3,1 \\
\hline \multicolumn{15}{|l|}{$\begin{array}{l}\text { Tipo de } \\
\text { delito/violência }\end{array}$} \\
\hline Física & 2959 & 47,4 & 2902 & 40,8 & 2468 & 29,7 & 2910 & 40,6 & 2574 & 46,7 & 1531 & 44,8 & 15444 & 40,6 \\
\hline Psioológica & 3081 & 49,3 & 3588 & 50,5 & 4157 & 49,8 & 3613 & 50,5 & 2936 & 51,3 & 1804 & 52,7 & 19179 & 50,5 \\
\hline Sexual & 102 & 1,6 & 510 & 7,2 & 138 & 1,6 & 542 & 7,5 & 80 & 1,4 & 45 & 1,3 & 1417 & 3,7 \\
\hline Outro & 105 & 1,7 & 108 & 1,5 & 1580 & 18,9 & 101 & 1,4 & 33 & 0,6 & 41 & 1,2 & 1960 & 5,2 \\
\hline \multicolumn{15}{|l|}{$\begin{array}{l}\text { Relaçăo entre o } \\
\text { acusado e a } \\
\text { vifima }\end{array}$} \\
\hline Conhecido & 6022 & 96,3 & 6425 & 90,4 & 7628 & 91,4 & 6563 & 91,6 & 5208 & 91 & 3125 & 91,4 & 34971 & 92 \\
\hline Desconlecido & 225 & 3,7 & 636 & 8,9 & 486 & 5,8 & 424 & 5,9 & 474 & 8,3 & 276 & 8 & 2522 & 6,6 \\
\hline Ignorado & 0 & 0 & 47 & 0,7 & 229 & 2,8 & 179 & 2,5 & 41 & 0,7 & 20 & 0,6 & 516 & 1,4 \\
\hline
\end{tabular}

Fonte: Instituto de Segurança Pública do Estado do Rio de Janeiro (ISP-RJ) 
No tocante aos locais de residência dessas mulheres, identificou-se que a maioria dos casos de violência aconteceu na região norte do município do Rio de Janeiro, com um valor de 22.066, correspondendo a 58,1\%.

Ao analisar a frequência do local de ocorrência da violência, a residência continua sendo o lugar com maior porcentagem descrita pelas mulheres dessa pesquisa durante os seis anos em estudo, correspondendo a $27.112(71,4 \%)$ do total de casos.

Por meio dos resultados, pode-se evidenciar o tipo de agressão sofrido por essas mulheres, prevalecendo a agressão psicológica, com o valor de 19.179 (50,5\%) do total. 0 elevado número de registros de violência psicológica é um dado importante, considerando que as mulheres agredidas estão reconhecendo um tipo de violência subjetiva, necessitando de julgamento e discernimento sobre seus direitos para reconhecer esse tipo de violência.

Outro fato que chamou atenção foi a relação entre o acusado e a vítima. Pelos registros, constatou-se que, na maioria dos casos, 34.971 (92\%), os agressores das mulheres em situação de violência de gênero eram conhecidos, eram maridos, companheiros, vizinhos ou parentes.

\section{DISCUSSÃO}

A pesquisa possibilitou caracterizar a demanda assistida nas DEAMs da região metropolitana do Rio de Janeiro, no período de 2003 a 2008, e analisar o perfil sociodemográfico da clientela diante da situação da violência de gênero à luz da discussão temática.

A maioria das mulheres que registrou a violência de gênero em boletim de ocorrência pertencia ao grupo em fase reprodutiva e economicamente ativa, conforme mencionado anteriormente. Os resultados indicam que estas mulheres são as que mais registraram a ocorrência da violência. Vários pesquisadores e estudiosos apontam as mulheres entre $15 \mathrm{e}$ 44 anos como as que mais vivenciaram a violência de gênero ${ }^{1,9}$. A situação é preocupante e é vista, tanto pela mulher agredida quanto pelo homem autor da violência, como uma questão de gênero em que o masculino prevalece sobre o feminino. As agressões, salvo exceções, sempre vêm de quem detém o poder na relação.

Em relação à cor, a maioria pertence à etnia branca. Um estudo revela que os agressores são homens e mulheres de cor branca em sua maioria, quando se toma como fonte os registros das instituições públicas de assistência a estas mulheres ${ }^{11}$. Supõe-se que as mulheres negras tendem a denunciar menos os seus agressores, sobretudo se negros. Elas tenderiam a protegê-los por medo dos estigmas que os acompanham na relação com os órgãos de repressão.

Quanto à escolaridade das mulheres investigadas, a maioria tinha o ensino fundamental completo. Podemos inferir neste estudo que as mulheres com menor nível de escolaridade são as que mais vivenciaram a violência de gênero. Por outro lado, é importante observar que estas mulheres reconhecem os seus direitos e têm informações quanto ao local para realizar o registro em Boletim de Ocorrência. Em uma pesquisa Ibope de 2008 sobre violência contra a mulher, em parceria com o Instituto Patrícia Galvão, realizada em todo país, constatou-se que, de um total de 2.002 pessoas entrevistadas sobre 0 assunto, $68 \%$ declararam conhecer a Lei Maria da Penha (Lei $\left.n^{0} 11.340 / 06\right)$, mesmo só de ouvir falar, e têm opiniões formadas sobre o conteúdo e o impacto da Lei. No conjunto do país, a população com menor renda familiar (até um salário mínimo) ou escolaridade (até a $4^{a}$ série) está no patamar mais baixo de conhecimento da referida Lei, representando, assim, uma taxa expressiva de $59 \%^{12}$.

No que se refere à situação conjugal das mulheres, observou-se que a maioria era solteira, sem vínculo matrimonial, o que sugere um fator predisponente para a denúncia à violência de gênero. Entretanto, a maioria dessas mulheres tem companheiro, mas não uma relação estável. Sentem-se inseguras, frágeis, dependentes financeiramente, tornando-se submissas; há medo de denunciar a violência e ter a punição do companheiro. De outra maneira, as mulheres casadas também formaram uma parcela considerável nesse estudo. Esta situação favorece que o companheiro se sinta "proprietário" da parceira, pensando estar no direito de praticar a violência em suas diferentes formas. Contrapondo os achados da presente pesquisa, estudiosos no assunto mostram que, entre as mulheres que vivenciaram violência de gênero, de um total de 265 , a maioria estava casada legalmente $(40,8 \%)$ ou vivia com o companheiro na época da entrevista $(59,2 \%)$, configurando-se o vínculo conjugal e o fato de estarem submersos nas tramas do silêncio e da vida conflituosa intrafamiliar.

Quanto à ocupação das participantes, constatou-se que a maioria dessas mulheres tinham atividades ligadas ao emprego doméstico, como faxineiras, copeiras, serventes e empregadas domésticas, entre outras remuneradas, e estas surgiram como as que mais vivenciaram a violência de gênero nessa pesquisa. Por outro lado, elas poderiam não ser necessariamente as mais vitimadas, entretanto, foram as que mais denunciaram os seus agressores.

As mulheres financeiramente dependentes tendem mais a se silenciar diante da agressão, justificando o medo de uma punição do agressor, a insegurança de fazer a denúncia, ou a falta de condições financeiras para se manter sozinhas; dependendo do companheiro. Nessa perspectiva, essas mulheres não denunciam seus agressores por inúmeros motivos: medo das ameaças e agressões, crença que continuar com o companheiro é melhor para os filhos, preconceitos e estereótipos de gênero, familiares ou culturais e, principalmente, pela dependência econômica ${ }^{13}$.

No que concerne aos bairros onde ocorreu a violência contra as mulheres, verificou-se que os bairros pertencentes à 
zona norte do município do Rio de Janeiro apresentaram maior frequência durante o período do estudo.

Em uma investigação realizada em 2003 pelo Sistema SESI/FIRJAN no Rio de Janeiro, obtiveram-se resultados semelhantes aos resultados desta pesquisa. Efetuou-se uma avaliação regional em que se verificou que os municípios da região da Baixada Fluminense merecem atenção especial, se for considerada a frequência de relatos de violência aos trabalhadores e/ou à família. Em segundo lugar, destacou-se a região metropolitana do Rio de Janeiro, seguida da região norte. As regiões de menores índices de mulheres que sofreram agressão no Estado foram centro-norte, noroeste e serrana ${ }^{14}$. Esses dados confirmam os resultados da presente pesquisa.

Uma lógica para o fato de a zona norte representar sempre a maioria nessas estatísticas é o fato de que essa região do município tem um maior quantitativo de bairros; em consequência, prevê um maior número de registros de ocorrências daquelas mulheres residentes nesta localidade.

A maioria das mulheres que registrou ocorrência relatou que a violência vivenciada foi na residência, o que restringe 0 número de pessoas que possam ter testemunhado a situação de violência. Nesse contexto, o homem sofre a violência nas ruas, nos espaços públicos, em geral, praticada por outro homem, e a mulher sofre a violência masculina dentro de casa, no espaço privado; seu agressor, em geral, é (ou foi) o namorado, o marido, o companheiro ou o amante ${ }^{15}$.

A agressão psicológica foi a forma de violência de gênero mais frequente, causando danos psicológicos e emocionais a essas mulheres, sendo uma dor invisível que requer intervenções dos profissionais da saúde e da segurança.

Em relação aos tipos de violência, mesmo que a violência física seja a mais reconhecida e socialmente considerada a mais perigosa, a agressão psicológica foi sentida por muitas mulheres nessa pesquisa como a mais dolorosa, danosa e demolidora ${ }^{16}$. As relações violentas tendem a obedecer uma escala progressiva durante os anos de relacionamento violento, iniciando com agressões verbais que passam para físicas e/ou sexuais, podendo chegar às ameaças de morte e homicídio ${ }^{17}$.

Os agressores geralmente foram pessoas conhecidas dessas mulheres, como marido, companheiro, amante, amigo ou vizinho. Esta situação corrobora a constatação dos autores que discutem a temática, reafirmando que a violência não se dá de um lado só. Há mulheres que também batem, agridem e humilham. A violência intrafamiliar se dá na relação, muitas vezes, na intimidade e no âmbito restrito do ambiente familiar. Em uma casa onde há violência contra a mulher, possivelmente há outros tipos de violência, em especial contra as crianças. A violência acaba por se transformar em uma forma de comunicação doentia e danosa; a família se torna a mais violenta das instituições, e a sociedade legitima a violência dentro de casa. No interior da família qualquer questão é passível de ser tratada com violência - as mais comuns são as relações homem/ mulher e com os filhos ${ }^{18}$.
A violência constitui ainda, um fenômeno que tem interfaces com a saúde coletiva, pois desponta como uma contradição na vida das mulheres, gerando tensão e resultando em processos destrutivos do seu processo saúde-doença. $A$ luta pela ampliação dos espaços de liberdade e de produção social da vida das mulheres deve ter como eixo norteador uma ruptura com a tradição do modelo de assistência hegemônico, de modo que a superação dessa realidade implica luta, enfrentamento nos planos político, ideológico, técnico, cultural e social ${ }^{7}$.

0 núcleo familiar configura-se como um espaço de construção da violência de gênero e de outras formas de violência. Assim, a violência doméstica contra a mulher constróise a partir das relações de desigualdade entre homens e mulheres, sendo naturalizada no processo de socialização dos sujeitos e reproduzida de geração a geração ${ }^{8}$.

Nesse sentido, é necessária a reestruturação da família fundamentada em relações mais simétricas entre homens e mulheres, entre pais e filhos, no ambiente familiar, possibilitando mudança na conformação dos comportamentos social e individual. É preciso que haja a consciência de sua história de violência, e que pessoas significativas ofereçam novos modelos de interação e inter-relações baseados em relações mais simétricas entre homens e mulheres, entre pais e filhos, que desconstruam as representações ancoradas no poder de um e submissão do outro, como meio de permitir a construção de relações familiares respeitosas e mais saudáveis ${ }^{8}$.

\section{CONSIDERAÇÕES FINAIS}

Os resultados do perfil sociodemográfico das mulheres que vivenciaram a situação de violência de gênero mostram que a maioria delas é jovem, tem baixo nível educacional, é solteira, de cor branca, está em idade reprodutiva, tem alguma ocupação remunerada, e sofre violência psicológica principalmente por parte do companheiro íntimo.

Estes resultados merecem estudos que aprofundem a temática, a fim de procurar esclarecer alguns aspectos associados à violência de gênero, como atitudes de submissão, opressão e medo diante do poder patriarcal do agressor do sexo masculino.

A maioria das mulheres que registrou em boletim de ocorrência os casos de violência é proveniente da região norte do município do Rio de Janeiro, o que pode ser um alerta para que políticas públicas sejam implementadas na região, a fim de reduzir o nível de violência. A própria residência é o local onde mais ocorre a violência de gênero, o que restringe o número de pessoas que possam ter testemunhado o fato.

Observa-se que o espaço familiar, onde deveria constituir-se em um refúgio de paz, harmonia e relacionamento das famílias, é, por excelência, o espaço em que a violência doméstica tem o seu ponto mais alto de incidência nas agressões intrafamiliares. Perpetradores ou agentes do abuso sexual, na 
maioria absoluta dos casos, são membros próximos da família. São estes que detêm o poder na relação e, muitas vezes, estão presentes em relações doentias, histórica e culturalmente construídas e legitimadas.

Nesta perspectiva, a mulher tem sido um dos principais alvos da violência, necessitando, cada vez mais, da atenção de profissionais, tanto da área jurídica quanto da área de saúde. Os enfermeiros, por fazerem parte da equipe de saúde que presta assistência à cliente em situação de violência, precisa ter um conhecimento sobre essa problemática e habilidade para realizar o cuidado no que se refere à escuta e ao acolhimento.

A qualidade da escuta exige de nós, profissionais enfermeiros, um comprometimento maior com a clientela e os serviços específicos de atenção às mulheres em situação de violência de gênero, principalmente nas unidades de atenção básica à saúde. A violência intrafamiliar é, uma forma de expressão das famílias, sendo necessária a mudança de paradigma de civilização na sociedade, o que certamente se traduzirá como a corrida pela paz e em busca de relações de gênero mais humanas, dignas, harmônicas e respeitáveis.

\section{REFERÊNCIAS}

1 - Galvão EF, Andrade SM. Violência contra a mulher: análise de casos atendidos em serviço de atenção à mulher em município do Sul do Brasil. Saude Soc. 2004 maio/agosto; 13(2).

2 - Nobre MT, Barrreira C. Controle social e mediação de conflitos: as delegacias da mulher e a violência doméstica. Sociologias. Porto Alegre. 2008; 10(20): 138-63.

3 - Rosa AG, Boing AF, Büchele F, Oliveira WF, Coelho EBSA. Violência conjugal contra a mulher a partir da ótica do homem autor da violência. Saude Soc. 2008 jul/set; 17(3).

4 - Kronbauer JFD, Meneghel SN. Perfil da violência de gênero perpetrada por companheiro. Rev Saude Publica. 2005 out; 39(5).

5 - Fernandes ETX. Cada mulher brasileira, uma cidadã. Programa de prevenção, assistência e combate à violência contra a mulher- Plano Nacional. Diálogos sobre a violência doméstica e de gênero: construindo políticas públicas. Brasilia (DF): Secretaria Especial de Políticas para as Mulheres; 2003 ago. p. 9.

6 - Marinheiro ALV, Vieira EM \& Souza L. Prevalência da violência contra a mulher usuária do serviço de saúde. Rev Saude Publica. 2006; 40(4): 604-10.

7 - Guedes RN, Silva ATMC, Fonseca RMGS. A violência de gênero e o processo saúde-doença das mulheres. Esc Anna Nery. 2009 jul/set; 13(3): 625-31.
8 - Gomes NP, Diniz NMF, Araújo AJS, Coelho TMF. Compreendendo a violência doméstica a partir das categorias de gênero e geração. Acta Paul Enferm. 2007 out./dez; 20 (4): 103.

9 - Schraiber LB, Oliveira AFPLD, Junior IF, Diniz S, Portella AP, Ludemir AB, et al. Prevalência da violência contra a mulher por parceiro íntimo em regiões do Brasil. Rev Saude Publica. 2007 out; 41(5): 797-809.

10 - Portal da Polícia Civil do Estado do Rio de Janeiro. [citado $2011 \mathrm{dez}$ 10]. Disponível em: http://www.policiacivil.rj.gov.br/delegacia.asp\#deam.

11 - Carneiro S. Mulheres negras, violência e pobreza. Secretaria Especial de Políticas para as Mulheres. Programa de prevenção, assistência e combate à violência contra a mulher- Plano Nacional. Diálogos sobre a violência doméstica e de gênero: construindo políticas públicas. Brasilia(DF); 2003 ago. p. 11.

12 - Portal da Agência Patrícia Galvão. [citado 2010 ago 22]. Disponível em: http://www.patriciagalvao.org.br/pesquisaibopeavon2009.htm

13 - Presser AD, Meneghel SN, Hennigton EA. Mulheres enfrentando as violências: a voz dos operadores sociais. Saude Soc. 2008 jul/set; 17(3): 104.

14- Serviço Social da Industria- SESI. 0 trabalhador da indústria e a segurança pública. Rio de Janeiro: Federação das Indústrias do Estado do Rio de Janeiro. 2003 ago; p. 3.(Pesquisa especial)

15 - Fernandes ETX. Cada mulher brasileira, uma cidadã. Programa de prevenção, assistência e combate à violência contra a mulher.Plano Nacional: diálogos sobre a violência doméstica e de gênero- construindo políticas públicas. Brasilia(DF): Secretaria Especial de Políticas para as Mulheres; 2003. ago; p. 9.

16 - Ministério da Saúde.(BR) Sementes do SUS. Sapucaia do Sul: IB Saúde; 2007. v. 2.

17 - Diniz NMF, Lopes RLM, Gesteira SMA. Violência conjugal: vivências expressas em discursos masculinos. Rev Esc Enferm USP. 2003; 37(2): 80.

18 - Dominguez B,Machado K. Lei Maria da Penha: limites ou possibilidades. Radis: comunicação em saúde. 2010 abr; 92:11. 